Article

\title{
Response of Preferential Soil Flow to Different Infiltration Rates and Vegetation Types in the Karst Region of Southwest China
}

\author{
Xiaoqing Kan ${ }^{1,2} \mathbb{D}$, Jinhua Cheng ${ }^{1,2, *}$ and Fang Hou ${ }^{1,2}$ \\ 1 College of Soil and Water Conservation, Beijing Forestry University, No. 35 Qinghua, East Road, \\ Haidian District, Beijing 100083, China; 18811374012@163.com (X.K.); CHNhoufang@163.com (F.H.) \\ 2 Jinyun Forest Ecosystem Station, School of Soil and Water Conservation, Beijing Forestry University, \\ No. 35 Qinghua East Road, Haidian District, Beijing 100083, China \\ * Correspondence: jinhua_cheng@126.com; Tel.: +86-(0)10-6233-8040
}

Received: 20 May 2020; Accepted: 16 June 2020; Published: 22 June 2020

\begin{abstract}
The widespread preferential flow phenomenon has an important impact on the water resource allocation of vegetation restoration in karst regions. In this study, four kinds of water infiltration experiments were conducted on six kinds of vegetation types (Pinus yunnanensis Franch. var. tenuifolia plantation forestlands, Eucalyptus robusta Smith plantation forestlands, Platycladus orientalis (L.) Francoptmxjjkmsc plantation forestlands, secondary forestlands, scrublands, and natural grasslands) separately to evaluate the effect of vegetation restoration on preferential flow in karst regions. The distribution of soil water infiltration was visualized via Brilliant Blue staining (290 images of soil vertical section staining) and data were processed via structural equation model (SEM). Results showed that $15-35 \mathrm{~mm}$ water accumulation was beneficial to the visualization of preferential flow. The experimental statement of a higher matrix flow in grassland than in plantations made it possible to draw conclusions of economic importance. Therefore, undergrowth of vegetation coverage in plantation forestlands should be increased. Experimentally analyzing the water-vegetation-soil interaction, shows an increase in vegetation coverage inhibits the development of matrix flow, an increase in soil erodibility may inhibit the development of preferential flow, and an increase in soil clay content may promote the deepening of matrix flow depth. The artificial forest can improve the soil structure and can effectively restore the degree of soil fragmentation; vegetation can be restored reasonably to prevent desertification in karst regions. Therefore, identifying and analyzing the structure characteristics of the soil macropore network under the conditions of natural vegetation communities and artificial vegetation communities in karst-geologic settings is an urgent study, which can provide a reference for improving the restoration measures of artificial forests and sustainable forestry development in karst desertification areas.
\end{abstract}

Keywords: preferential flow; dye tracer; plantation forestlands; soil erodibility factor; interaction of water-vegetation-soil

\section{Introduction}

The karst region in Southwest China is the domain with the largest area and the strongest karst development in the world [1]. The karst ecosystem is fragile and the special dual structure of earth and rock increases the connectivity of macropores [2], which is conducive to the rapid infiltration (preferential flow) and leakage of surface water [3]. It is easy to form karst rocky desertification without vegetation protection [4]. As the main body of karst ecosystem, vegetation plays an important role in maintaining the ecological service function of karst ecosystem [5]. Therefore, vegetation restoration and 
reconstruction are the key research of karst ecosystem restoration [6]. However, due to the special soil structure vegetation restoration is restricted by water and nutrients [7]. However, vegetation coverage can reflect root system status [8] and root system can reflect soil structure [9]; the heterogeneity of soil structure will lead to the change of soil hydraulic properties [10]. Therefore, it is of great significance to understand the hydrological process of the surface soil after vegetation improvement.

The influence of preferential flow on hydrological process is the most important [11,12]. Preferential flow is a non-equilibrium flow process in which water moves rapidly around a certain area in soil space while matrix flow is a balanced flow process [13]. In karst region, fractures and macropores are connected to each other [14], preferential flow arise easily [15]. Because the surface runoff coefficient on the hillside is always less than $5 \%$ [16], the precipitation in this area supplies most of the groundwater through infiltration which is not conducive to the restoration of surface vegetation. Preferential flow not only affects hydrological cycle, but also soil erosion and hillside stability $[17,18]$. Soil with high organic carbon content may not be susceptible to preferential flow [19]. However, especially in karst regions, the priority flow and potential erodibility of soil still need further study. Therefore, the mechanism of preferential flow in karst region needs to be studied [20].

Soil is the participant and carrier of many ecological processes in ecosystems and is one of the key contents of ecosystem function restoration and maintenance [21]. Previous studies have shown that physical properties [17] such as soil structure [22] and soil texture [23] have a great influence on preferential flow. Soil structure includes solid components, pore space, and its interface [24]. Soil texture includes organic matter [25] and soil particle size [26]. Different soil structures in karst region results in different infiltration rates [20]. A better understanding of the relationship between soil structure and preferential flow will help to understand complex hydrological processes [20].

In this study, natural sites (secondary forest, grassland) were used as reference samples to compare and analyze the contribution of plantation to local soil and hydrology. By a dye tracing method [27] and SEM analysis, (1) the characteristics of water preferential transport under different infiltration water conditions were discussed; (2) this paper reveals the soil environmental characteristics of different forest lands in karst region and its influence on the occurrence and development of preferential flow and explains the importance of artificial forest restoration to local soil; (3) the relationship between soil erodibility and preferential flow was analyzed. The research results have profound theoretical significance for further understanding the unique hydrological process in southwest karst region, enriching the research contents of hydrology and soil water kinematics. It is also of great practical significance to promote vegetation restoration and sustainable economic and environmental development in karst region.

\section{Materials and Methods}

\subsection{Site Description}

Field experiments were conducted in forest soil from July 2018 to August 2018 in the Yangjie Catchment $\left(102^{\circ} 55^{\prime \prime}\right.$ E, $\left.23^{\circ} 37^{\prime \prime}-23^{\circ} 44^{\prime \prime} \mathrm{N}\right)$ in the southwestern karst region of Jianshui Town in Yunnan Province (Figure 1), China [28]. The altitude is $1350-1700 \mathrm{~m}$. The annual average temperature is $19.8^{\circ} \mathrm{C}$, and the annual average temperature of the land surface is $20.8^{\circ} \mathrm{C}$. The average annual sunshine hours are $2322 \mathrm{~h}$, and the average annual precipitation is $805 \mathrm{~mm}$. Red soil is the main soil type affected by parent material. The plantation forestry was planted in 1985, and its recovery time is more than 30 years. Thus, the forest soil structure is stable. Secondary forestland has been restored since 1970 and no human disturbance was observed in the secondary forestland and grassland. The grassland and secondary forest belong to the primitive vegetation community, the Pinus yunnanensis Franch. var. tenuifolia forest has strong barren tolerance and is a native tree species, the Eucalyptus robusta Smith forest has high economic value, and the Platycladus orientalis (L.) Francoptmxjjkmsc forest has strong drought resistance. The rock contents of secondary forestland (SF), grassland (G), Pinus yunnanensis Franch. var. tenuifolia plantation forestland (PY), Eucalyptus robusta Smith plantation forestland 
(EF), Platycladus orientalis (L.) Francoptmxjjkmsc plantation forestland (CF) and scrubland (S) are approximately 30\%,10\%,5\%, 0\%, 0\% and 15\%, respectively. Additional detailed information on the geology of the study area, the geomorphological characteristics of the environment, and a more extensive climatic description have been provided by Kan et al. (2019) [28].

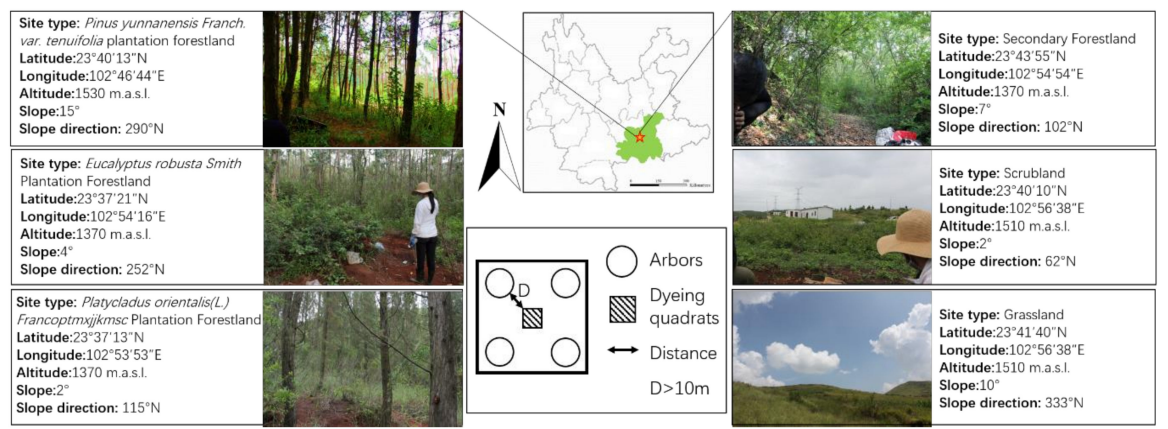

Figure 1. Basic situation of the experimental sites in Yunnan Province, China.

We randomly selected sample plots in these six vegetation environments, including 8 experimental plots for secondary forest, 10 experimental plots for Pinus yunnanensis Franch. var. tenuifolia plantation forestland, 12 experimental plots for Eucalyptus robusta Smith plantation forestland, 8 experimental plots for Platycladus orientalis (L.) Francoptmxjjkmsc plantation forestland, 8 experimental plots for shrub plantation, and 12 experimental plots for natural grassland because they are all arranged at the foot of slope. The direction of the slope is the average degree from the north. The number of the experimental plots (58 in total) is far more than the known number of the priority flow study plots, and the experiment can be replicated in the karst plantation area (Figure 1). The plant species with the highest importance value in the same community is the dominant species of the community. Therefore, the coverage value (trees canopy density, shrubs coverage ratio, herbs coverage ratio) of dominant species is used as a parameter to represent the growth diversity of local plants. It is considered that the general rules can be summarized and can provide some guidance for the artificial restoration of special environments around the world. There is no river around the experimental site and atmospheric precipitation is an important way of soil water supply.

\subsection{Physical Properties of Soil}

Each site used the cutting ring infiltration method to measure physical properties of soil. Fresh weight was $m_{1}$. After $12 \mathrm{~h}$ of water absorption, the rings weighed $m_{2}$. The rings were weighed $m_{3}$ after $12 \mathrm{~h}$ of penetration by dry sand. Then, the rings were weighed $m_{4}$ after another $12 \mathrm{~h}$. The cutting rings weighed $m_{5}$ after baking in a $105^{\circ} \mathrm{C}$ oven for $24 \mathrm{~h}$. The weight of the cutting rings was $m_{6}$. The volume of each cutting rings was $v$. The calculation formula is as follows $[29,30]$ :

$$
\begin{gathered}
P(\%)=\left[\left(m_{2}-m_{5}\right) / v\right] \times 100 \%, \\
P_{1}(\%)=\left[\left(m_{3}-m_{5}\right) / v\right] \times 100 \%, \\
P_{2}(\%)=P-P_{1}, \\
P_{3}(\%)=\left[\left(m_{2}-m_{5}\right) /\left(m_{5}-m_{6}\right)\right] \times 100 \%, \\
P_{4}(\%)=\left[\left(m_{3}-m_{5}\right) /\left(m_{5}-m_{6}\right)\right] \times 100 \%, \\
P_{5}(\%)=\left[\left(m_{4}-m_{5}\right) /\left(m_{5}-m_{6}\right)\right] \times 100 \%, \\
P_{6}(\%)=\left[\left(m_{1}-m_{5}\right) /\left(m_{5}-m_{6}\right)\right] \times 100 \%,
\end{gathered}
$$

Saturated hydraulic conductivity was determined using a constant water head and an ST-70A soil moisture permeameter. Thirty-second permeability should be measured every $10 \mathrm{~min}$ in the previous 
hour, then $30 \mathrm{~s}$ permeability should be measured every $30 \mathrm{~min}$ until stable permeability is reached. In accordance with Darcy's law, the calculation formula for the saturated hydraulic conductivity $K_{s}$ of soil is as follows [31]:

$$
K_{s}=\frac{V}{t A} \cdot \frac{L}{H},
$$

where $K_{s}$ is the saturated hydraulic conductivity $\left(\mathrm{cm} \cdot \mathrm{min}^{-1}\right), H$ is the head pressure at the inlet end $(\mathrm{cm}), V$ is the amount of water through the cross-sectional area $\left(\mathrm{cm}^{3}\right), t$ is the water outflow time $(\mathrm{min})$, $L$ is the length of soil column $(\mathrm{cm})$, and $A$ is the cross-sectional area of the soil column $\left(\mathrm{cm}^{2}\right)$.

Williams et al. (1990) [32] developed the calculation formula for soil erodibility factor $K$ value in relation to the sand, silt, clay, and soil organic carbon contents using the erosion productivity impact calculator (EPIC) evaluation model.

$K$ value in the EPIC model is used as an index to measure coefficient of soil erodibility. The formula of $K$ is as follows:

$$
\begin{aligned}
& K=\left\{0.2+0.3 \exp \left[-0.0256 S A N\left(1-\frac{S I L}{100}\right)\right]\right\}\left(\frac{S I L}{C L A+S I L}\right)^{0.3} . \\
& \left(1.0 \frac{0.25 \mathrm{C}}{\mathrm{C}+\exp (3.72-2.95 \mathrm{C})}\right)\left(1.0 \frac{0.7 \mathrm{SNI}}{\operatorname{SNI}+\exp (-5.51+22.9 S N I)}\right) \text {, }
\end{aligned}
$$

where $S A N$ is the sand content (\%), SIL is the powder content (\%), CLA is the clay content (\%), C is the organic carbon content (\%), and SNI $=1-S A N / 100$.

In the calculation formula of the $K$ value of the soil erodibility factor, the standard of soil particle analysis is usually made in the United States. In the second National Soil Census, the international system was used for soil particle analysis; hence, the international system must be converted into the American system.

\subsection{Dyeing Experiment}

Secondary and plantation forests with a stable soil structure and reduced disturbance were selected [27] under similar environmental characteristics at least three weeks after rainfall to remain dry prior to the dye experiment [33]. Each transect included five vertical sections and we requested the sample sites to be located at least $10 \mathrm{~m}$ from each other to avoid interferences in the experiments [34]. At each site, plastic sheets with a length $\times$ width $\times$ height of $0.6 \mathrm{~m} \times 0.6 \mathrm{~m} \times 0.3 \mathrm{~m}$ were used to surround the field. As a dye tracer, Brilliant Blue can visually show the distribution of non-uniform flow in soil, that is, preferential flow [35]. Therefore, a $4 \mathrm{~g} / \mathrm{L}$ dye solution was used in 36 tracing experiments [36]. According to rainfall data for the years 2008-2017 in our study region [28], the distribution of rainfall amounts was: for $<10 \mathrm{~mm}$ rain (light rain), $69 \%$ of the rainfall events; for $10.1-25 \mathrm{~mm}$ (moderate rain), $23 \%$ of events; for $25.1-50 \mathrm{~mm}$ (heavy rain), $7 \%$ of events; and for $>50.1 \mathrm{~mm}$ (storm), $2 \%$ of events. We used the one-dimensional ponded water infiltration method which has proved that the study of water infiltration under the condition of surface water accumulation is significant [37]. Our simulation experiments included rainfall amounts of $5 \mathrm{~mm}$ (a small rainfall event), $15 \mathrm{~mm}$ (median), $35 \mathrm{~mm}$ (large), and $55 \mathrm{~mm}$ (extreme), and the fields, images, and soil samples were numbered G5, G15, G35 and G55 according to the amount of Brilliant Blue solution used. The final data were collected in the $50 \mathrm{~cm} \times 50 \mathrm{~cm}$ staining area in the middle of the quadrant, and each quadrant was cut into five vertical sections with $10 \mathrm{~cm}$ spaces between each other. We photographed each vertical section using a Canon 500D digital camera. In cases of bright sunlight, we used a parasol to reduce shadow interference [38].

The photos were processed in Photoshop CS3 (Adobe Systems Inc., San Jose, CA, USA) and Image Pro Plus 6.0 (Media Cybernetics Inc., Rockville, MD) to quantify the stained areas [39]. Image analysis geometrically corrected the captured images by using Photoshop CS3. The sizes of the vertical sections of the pictures were cropped to $50 \mathrm{~cm} \times 50 \mathrm{~cm}$ by referring to the image ruler. Then, the saturation, brightness, greyscale and threshold values were adjusted. The processed images were digitised using Image Pro Plus 6.0, and the pixel of each image was set to $500 \times 500$ to convert the image into binary information classified into black (pixel value 0 , represents the dye position) and white (pixel value 255, 
represents the undyed position). Additional detailed information on the calculation of the parameters of soil vertical section dyeing morphology, including depth of matrix flow (UF/cm), infiltration depth $(\mathrm{ID} / \mathrm{cm})$, dye coverage $(\mathrm{DC} / \%)$, preferential flow fraction $(\mathrm{PF})$, length index $(\mathrm{Li})$, variation coefficient of dye coverage in preferential flow area $(\mathrm{CV})$, variation coefficients of maximum infiltration depths $(\mathrm{C} \mu)$, and SEM have been provided by Kan et al. (2019) [28].

\section{Results}

\subsection{Soil Texture}

Different from the pollutant diffusion models of the Loess Plateau [34] and wetland [40], karst regions need further study. Therefore, the relationship between surface water infiltration and preferential flow caused by ponding must be studied. The six experimental environment types according to soil physical properties are illustrated in Table 1. A box-whisker plot is drawn on the basis of the data of soil bulk density and porosity, as shown in Table 1 . The mean value $(\mathrm{Xm})$ of the total porosity of scrubland soil is larger than that of other site types; accordingly, the total porosity of scrubland site is larger than that of other site types. The distance between the upper (maximum) and lower (minimum) edges of secondary forestlands is the smallest, indicating that the total porosity of the secondary forestlands is minimally scattered and that the difference is small. The value of the interquartile range (IQR = Q3-Q1, where Q1 is the 25th percentage, and Q3 is the 75th percentage) of cypress forest is the lowest. The soil capillary porosity median $(\mathrm{Xm})$ of the six site types is similar, hence, the soil capillary porosity of the six experimental environment types is also similar. The mean value $(\mathrm{Xm})$ of soil noncapillary porosity and the distance between the upper and lower edges of grassland are the largest, indicating that the noncapillary porosity of grassland is relatively scattered. The mean value $(\mathrm{Xm})$ of the Eucalyptus robusta Smith plantation forestland is the smallest, which implies that the noncapillary porosity of the Eucalyptus robusta Smith plantation forestland is smaller than that of other plots. The maximum and minimum water-holding capacities of scrubland are higher than those of other experimental environment types in the mean $(\mathrm{Xm})$, upper and lower boundaries, and IQR. Therefore, the maximum and minimum water-holding capacities of scrubland are higher than those of the other experimental environment types, and their variation degree is larger. The maximum, minimum, field, and soil natural water-holding capacities of Pinus yunnanensis Franch. var. tenuifolia plantation forestland are the least. This result indicates that the water-holding degree of Pinus yunnanensis Franch. var. tenuifolia plantation forestland is smaller than that of the other site types and it forms surface runoff more easily.

According to the soil texture and the calculated soil erodibility factor, we draw a combination diagram, as shown in Table 1. The sand gravel and clay contents in secondary forestlands are the lowest and the highest, respectively. The sand and clay contents of Pinus yunnanensis Franch. var. tenuifolia plantation forestland are the largest and smallest, respectively. This result indicates that the soil viscosity of secondary forestlands is the largest, and the particle diameter is small. The soil viscosity of Pinus yunnanensis Franch. var. tenuifolia plantation forestland is the lowest, whereas that of Platycladus orientalis (L.) Francoptmxjjkmsc cypress plantation forestland is the largest amongst the three plantation types. Furthermore, the silt content of scrubland is the largest amongst the six experimental environment types. The soil of Eucalyptus robusta Smith plantation forestland is easy to erode, and Platycladus orientalis (L.) Francoptmxijkmsc cypress plantation forestland is less susceptible to soil erosion in comparison with the other site types. The possibility of grassland receiving soil erosion is close to that of secondary forestlands. Table 1 is drawn in accordance with the saturated hydraulic conductivity of the six site types. Grassland has the strongest water conductivity, but the standard deviation is large. The water conductivity of Eucalyptus robusta Smith plantation forestland is similar to that of scrubland, but the standard deviation of scrubland is larger. The standard deviation of secondary forestlands is similar to that of Pinus yunnanensis Franch. var. tenuifolia plantation forestland. The saturated hydraulic conductivity and standard deviation of Platycladus orientalis (L.) Francoptmxjjkmsc cypress plantation forestland were the smallest. 
Table 1. Physical and hydrological properties of soil (average value \pm standard deviation).

\begin{tabular}{|c|c|c|c|c|c|c|c|c|c|c|c|c|c|}
\hline \multirow{3}{*}{ Site Type } & \multicolumn{3}{|c|}{ Particle Size } & \multirow{2}{*}{$\mathrm{K}^{10}$} & \multirow{2}{*}{ BD $^{11}$} & \multirow{2}{*}{$\mathbf{P}^{12}$} & \multirow{2}{*}{$\mathbf{P 1}{ }^{13}$} & \multirow{2}{*}{$\mathrm{P2}^{14}$} & \multirow{2}{*}{ P3 ${ }^{15}$} & \multirow{2}{*}{$\mathbf{P 4}{ }^{16}$} & \multirow{2}{*}{ P5 ${ }^{17}$} & \multirow{2}{*}{$\mathbf{P 6}^{18}$} & \multirow{2}{*}{$\mathrm{Ks}^{19}$} \\
\hline & SAN $^{7}$ & SIL $^{8}$ & CLA $^{9}$ & & & & & & & & & & \\
\hline & (\%) & $(\%)$ & (\%) & $\left(10^{-10}\right)$ & $\left(\mathrm{g}^{\mathrm{cm}-3}\right)$ & $(\%)$ & (\%) & $(\%)$ & (\%) & (\%) & $(\%)$ & (\%) & $(\mathrm{cm} \mathrm{min}-1)$ \\
\hline $\mathrm{SF}^{1}$ & $0.61 \pm 0.50$ & $23.38 \pm 3.71$ & $76.01 \pm 3.63$ & $14.59 \pm 3.99$ & $1.12 \pm 0.12$ & $39.46 \pm 4.82$ & $35.90 \pm 3.93$ & $3.56 \pm 2.51$ & $35.83 \pm 7.27$ & $32.52 \pm 5.90$ & $30.32 \pm 5.37$ & $23.07 \pm 1.39$ & $0.0140 \pm 0.0047$ \\
\hline $\mathrm{PY}^{2}$ & $27.59 \pm 28.84$ & $40.55 \pm 8.08$ & $31.86 \pm 23.26$ & $232.77 \pm 212.23$ & $1.37 \pm 0.13$ & $37.91 \pm 3.74$ & $35.93 \pm 3.85$ & $1.98 \pm 1.44$ & $27.99 \pm 4.31$ & $26.45 \pm 3.49$ & $24.90 \pm 3.18$ & $23.00 \pm 2.39$ & $0.0115 \pm 0.0030$ \\
\hline $\mathrm{EF}^{3}$ & $2.86 \pm 0.44$ & $37.52 \pm 7.54$ & $59.63 \pm 7.57$ & $33.01 \pm 4.24$ & $1.02 \pm 0.07$ & $46.25 \pm 2.73$ & $43.13 \pm 2.29$ & $3.12 \pm 0.77$ & $45.56 \pm 5.19$ & $42.46 \pm 4.39$ & $40.49 \pm 4.47$ & $23.95 \pm 2.38$ & $0.0246 \pm 0.0074$ \\
\hline $\mathrm{CF}^{4}$ & $3.67 \pm 4.38$ & $22.65 \pm 5.78$ & $73.69 \pm 8.85$ & $2.66 \pm 1.04$ & $1.16 \pm 0.05$ & $40.81 \pm 2.91$ & $37.99 \pm 2.55$ & $2.82 \pm 1.11$ & $35.25 \pm 2.23$ & $32.85 \pm 2.46$ & $30.78 \pm 2.33$ & $27.70 \pm 0.44$ & $0.0046 \pm 0.0008$ \\
\hline $\mathrm{S}^{5}$ & $2.06 \pm 0.95$ & $54.11 \pm 28.74$ & $43.83 \pm 29.28$ & $10.67 \pm 13.73$ & $1.06 \pm 0.11$ & $38.88 \pm 1.64$ & $37.66 \pm 1.85$ & $1.23 \pm 0.80$ & $37.19 \pm 4.65$ & $36.01 \pm 4.56$ & $33.70 \pm 4.43$ & $33.26 \pm 3.26$ & $0.0291 \pm 0.0129$ \\
\hline $\mathrm{G}^{6}$ & $8.03 \pm 8.15$ & $43.86 \pm 22.36$ & $48.11 \pm 18.05$ & $319.64 \pm 428.49$ & $1.05 \pm 0.18$ & $40.14 \pm 6.82$ & $37.30 \pm 6.01$ & $2.84 \pm 1.97$ & $40.56 \pm 13.54$ & $37.43 \pm 11.25$ & $34.43 \pm 10.00$ & $26.51 \pm 8.14$ & $0.0356 \pm 0.0058$ \\
\hline
\end{tabular}




\subsection{Preferential Flow Characteristic}

\subsubsection{Comparison of the Change Characteristics of the Dyeing Area}

On the basis of the field dyeing experiments of different site types and infiltration heads, a total of 290 dyeing images are obtained. Twenty-four examples of vertical section dyeing images are selected, as shown in Figures 2 and 3. The depth of uniform infiltration can represent the depth of the uniform infiltration front. The dye coverage of this depth is $80 \%$ and belongs to matrix flow; the dye coverage of other parts belongs to preferential flow [28]. The dyed images present that the ratio of the dyed area decreases with an increase in infiltration head [38]. The existence of preferential flow can be proven by the uneven distribution of the dyeing area [39].
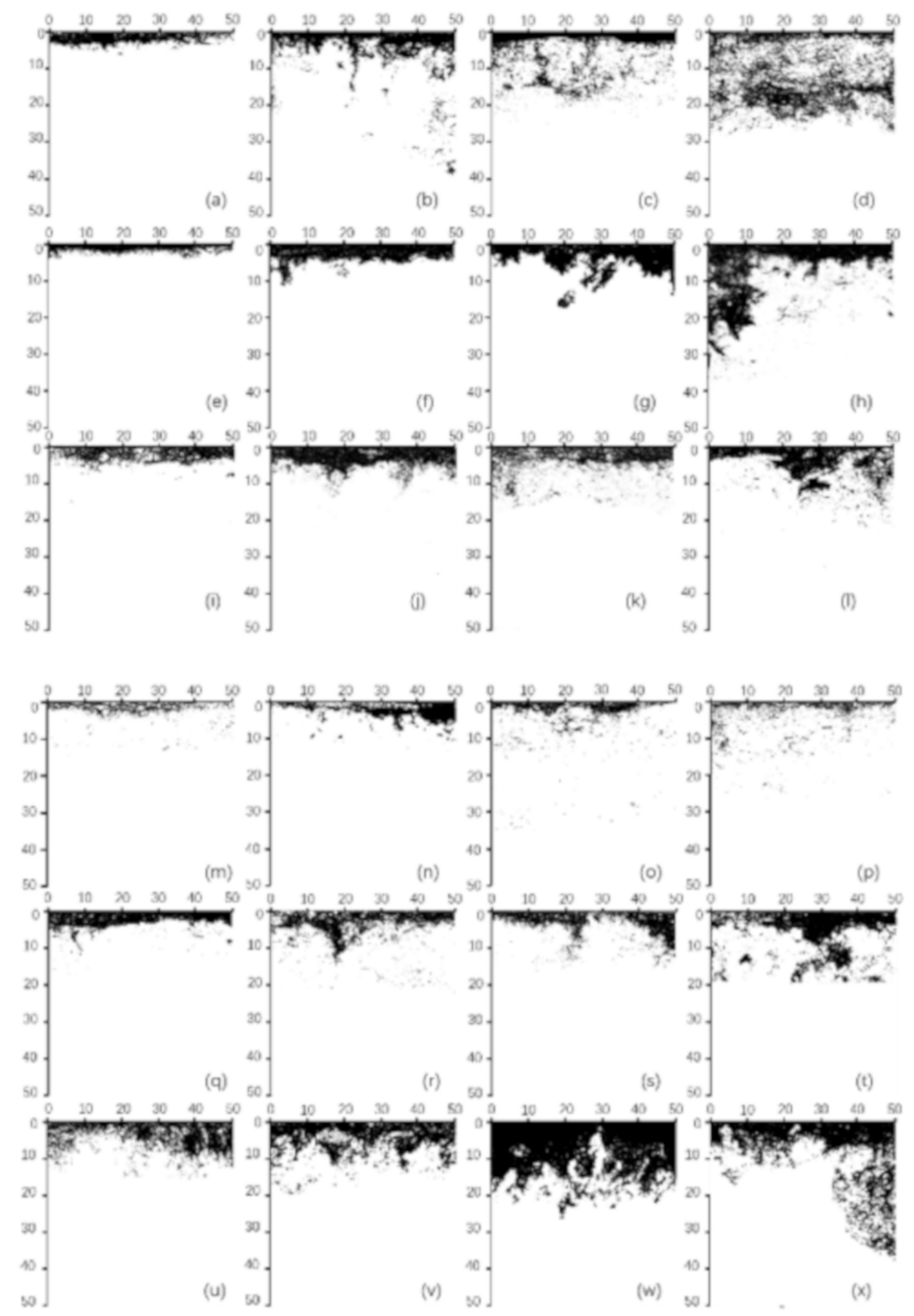

Figure 2. Example dyeing images for vertical soil sections in the three types of sites under different precipitation amounts. (a-d) correspond to the vertical sections of Pinus yunnanensis Franch. var. tenuifolia plantation forestland at G5, G15, G35 and G55, respectively; (e-h) refer to the vertical sections of secondary forestlands at G5, G15, G35 and G55, respectively; (i-1) correspond to the vertical sections of Eucalyptus robusta Smith plantation forestland at G5, G15, G35 and G55, respectively; (m-p) correspond to the vertical sections of Platycladus orientalis (L.) Francoptmxjjkmsc cypress plantation forestland at G5, G15, G35 and G55, respectively; (q-t) correspond to the vertical sections of scrubland at G5, G15, G35 and G55, respectively; $(\mathbf{u}-\mathbf{x})$ correspond to the vertical sections of grassland at G5, G15, G35 and G55, respectively. G5, G15, G35 and G55 correspond to 5, 15, 35, and $55 \mathrm{~mm}$ ponded water infiltration simulations, which simulate the change in ponded water in light rain, medium rain, heavy rain, and storm, respectively. 


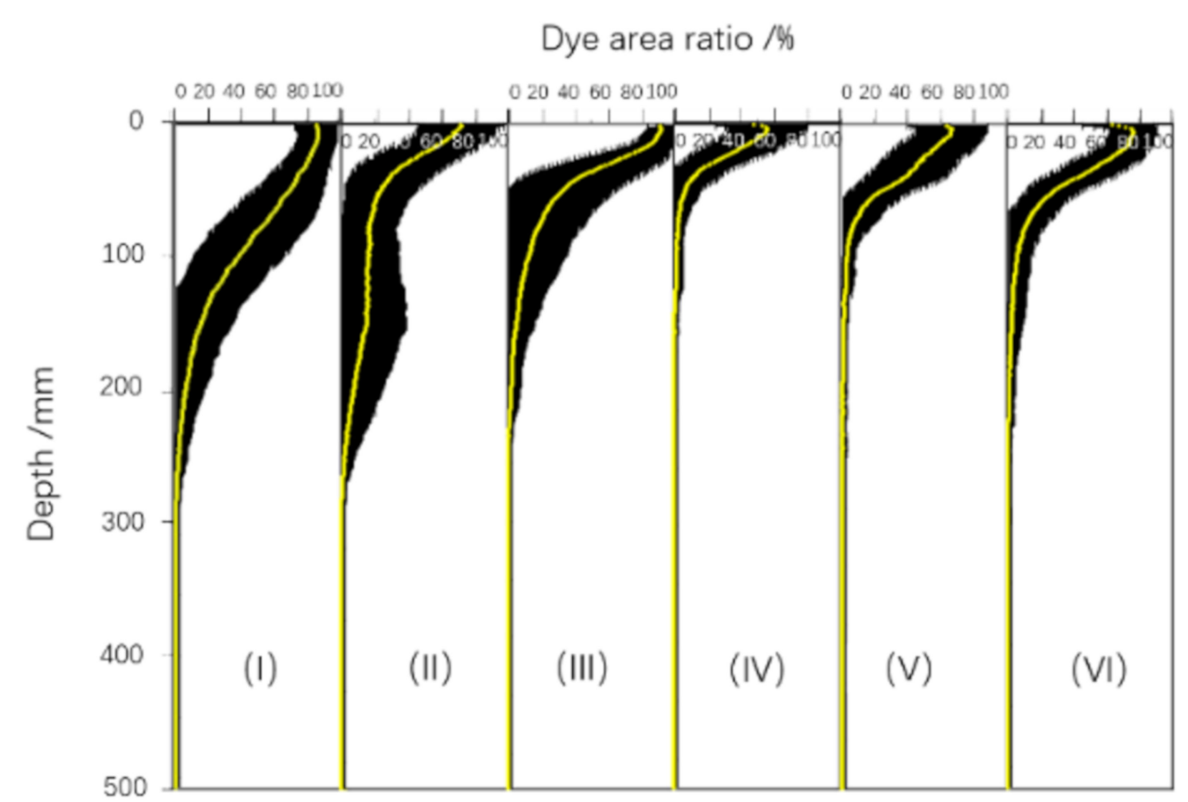

Figure 3. Average of the dyeing area and the standard deviation curve of different observation plots. (I) corresponds to grassland, (II) corresponds to secondary forestlands, (III) corresponds to Pinus yunnanensis Franch. var. tenuifolia plantation forestland, (IV) corresponds to Platycladus orientalis (L.) Francoptmxjjkmsc cypress plantation forestland, (V) corresponds to Eucalyptus robusta Smith plantation forestland, and (VI) corresponds to scrubland.

After the numerical treatment of each vertical section, Figure 2 is obtained. The preferential flow characteristics of each site condition under different infiltration head conditions are evident (Figure 3). With deepening soil depth, the flow pattern gradually changes from matrix flow to preferential flow. The dyeing area ratio decreases with an increase in soil depth, indicating that the infiltration process is nonuniform and that preferential flow occurs. The development degree of preferential flow is different and a large standard deviation can reflect the heterogeneity of the spatial distribution of preferential flow. The infiltration depths of grassland and secondary forestlands are the largest which can reach $30 \mathrm{~cm}$, those of Pinus yunnanensis Franch. var. tenuifolia plantation forestland and scrubland which almost reach $25 \mathrm{~cm}$, are shallower, and those of Platycladus orientalis (L.) Francoptmxjjkmsc cypress plantation forestland and Eucalyptus robusta Smith plantation forestland are the shallowest around 15 $\mathrm{cm}$. Therefore, under the similar water infiltration conditions, the vertical water infiltration depth of natural site is the largest. However, the standard deviation of matrix flow is small, the values of matrix flow staining in secondary forestlands, Platycladus orientalis (L.) Francoptmxjjkmsc cypress plantation forestland, and Eucalyptus robusta Smith plantation forestland are small, and the standard deviation is large. The average dyeing area ratio curve of each site condition is standard but the standard deviation of Pinus yunnanensis Franch. var. tenuifolia plantation forestland is concentrated. The standard deviation of secondary forestlands fluctuates greatly. The difference in water infiltration process of secondary forestlands is the largest and the ratio difference of other site conditions is uniform.

\subsubsection{Analysis of the Variation in Dyeing Area}

The dyeing experiment can directly obtain the dyed vertical section image (Figures 2 and 3), however, the results under different conditions cannot be quantitatively analyzed so we need to convert the image into data that can be quantitatively analyzed. Depth of matrix flow $(\mathrm{UF} / \mathrm{cm})$ is an observed variable which is used to show the maximum depth of uniform water infiltration under different environmental characteristics and infiltration conditions. Infiltration depth $(\mathrm{ID} / \mathrm{cm})$ is an observed variable which is used to describe the maximum depth of non-uniform infiltration of water and it can represent the fastest movement depth of water under different conditions. Dye coverage (DC/\%) 
is a latent variables, refers to the percentage ratio of the dyed area, which can used to compare the difference of dyeing area between different depths and analyze the relationship between dyeing area and depth. Preferential flow fraction $(\mathrm{PF} / \%)$ is used to reflect the distribution and degree of preferential flow. A high PF value indicates a high degree of preferential flow. Length index (Li/\%) of preferential flow can describe the degree of heterogeneity of preferential flow. The variation coefficient of the dye coverage in the preferential flow area (CV) is used to quantitatively describe the change in dyeing morphology after the removal of the matrix flow areas. The variation coefficients of maximum infiltration depths $(\mathrm{C} \mu)$ are used to describe the non-uniform characteristics of soil water flow in vertical slices, which can describe the difference of water infiltration depth under similar conditions. These indexes are used to analyze the morphological characteristics and development degree of preferential flow and reveal the nonuniform characteristics of preferential flow under different infiltration water conditions (Tables 2-5).

Tables 2-5 present the characteristic values of preferential flow such as depth of matrix flow, infiltration depth, dye coverage, preferential flow fraction, and length index, of secondary forestlands and natural grassland are greater than those of planted forest. For example, depth of matrix flow, dye coverage and length index of grassland are the largest, infiltration depth of plantation forestlands are smaller than natural sites, preferential flow fraction is $\mathrm{SF}>\mathrm{EF}>\mathrm{CF}>\mathrm{S}>\mathrm{G}>\mathrm{PY}$ which is consistent with the results in Figure 3. However, the variation coefficient of dye coverage in preferential flow area $(\mathrm{CV})$ and variation coefficients of maximum infiltration depths $(\mathrm{C} \mu)$ of the plantation are higher than those of the natural site. CV of forestlands are larger than grassland and shrubs, $\mathrm{C} \mu$ of plantation forestlands are larger than natural sites. The results show that the preferential flow of plantation is higher than that of natural forest and grassland.

Different site conditions produce different preferential flow, whereas different head pressures cause different preferential flows. Comparing Table 2 with Table 4, the depth of matrix flow of G35 is the largest (almost twice that of G5). And comparing Table 3 with Table 5, the depth of matrix flow of G55 and G15 are almost equal. The infiltration depth, dye coverage, preferential flow fraction, and length index of G55 are much higher than those of the three other infiltration head types (Table 6). The value of G5 is the smallest and is enough to show that a close relationship exists between infiltration water quantity and preferential flow (Table 2). The preferential flow fraction and CV of the four infiltration water conditions are similar but the CV of G5 is considerably larger than those of the three other treatment methods and almost 1.5 times of that of G35 (Tables 2 and 4). However, the depth of matrix flow of G5, G15, G35, and G55 are $9.06 \%, 10.69 \%, 14.27 \%$ and $9.17 \%$ of their infiltration depths, respectively, indicating no substantial difference in the proportion of matrix flow depth amongst the four treatments (Tables 2-5).

\subsection{Correlation of Characteristic Parameters Based on Structural Equation}

SEM can be used to analyze the experimental data of preferential flow because it considers the correlation between variables and errors [28]. Twenty-six indexes of vegetation characteristics, soil properties, and preferential flow characteristic parameters exist. These indexes include the relatively repetitive ones. We select the clay content, preferential flow fraction, and total porosity of the soil (P) values with the highest PC coefficient in vegetation, soil, and preferential flow characteristic parameters and soil porosity via principal component analysis (Table 6). We also select the generation with the highest PC coefficient to clarify the logical relationship amongst the factors. Soil erodibility (K), degree of precipitation (RF), saturated conductivity of soil (Ks), and depth of matrix flow are analyzed via SEM. In this study, SEM is used to construct and evaluate the index system that can reflect the relationship between potential variables (exogenous and endogenous potential variables) [41]. We use AMOS 7.0 software to establish the SEM equation. 
Table 2. Characteristic parameters of preferential flow variables. (G5). (average value \pm standard deviation).

\begin{tabular}{|c|c|c|c|c|c|c|c|c|}
\hline Site Type & Sample Number & $\mathrm{UF}^{1} / \mathrm{cm}$ & $\mathrm{ID}^{2} / \mathrm{cm}$ & $\mathrm{DC}^{3} / \%$ & $\mathrm{PF}^{4} / \%$ & $\mathrm{Li}^{5} / \%$ & $\mathrm{CV}^{6}$ & $\mathrm{C} \mu^{7}$ \\
\hline \multirow{2}{*}{ SF } & 1 & $0.12 \pm 0.04$ & $5.10 \pm 0.66$ & $2.94 \pm 1.30$ & $0.99 \pm 0.00$ & \multirow{2}{*}{$5.31 \pm 2.16$} & \multirow{2}{*}{$0.41 \pm 0.09$} & \multirow{2}{*}{$0.0020 \pm 0.0012$} \\
\hline & 2 & $0.10 \pm 0.06$ & $7.26 \pm 2.68$ & $2.19 \pm 0.62$ & $0.99 \pm 0.00$ & & & \\
\hline \multirow{3}{*}{ PY } & 1 & $1.56 \pm 1.43$ & $5.20 \pm 1.29$ & $4.22 \pm 0.66$ & $0.92 \pm 0.08$ & \multirow{3}{*}{$13.52 \pm 4.46$} & \multirow{3}{*}{$0.30 \pm 0.09$} & \multirow{3}{*}{$0.0032 \pm 0.0016$} \\
\hline & 2 & $1.38 \pm 0.76$ & $7.60 \pm 1.49$ & $6.12 \pm 2.10$ & $0.96 \pm 0.01$ & & & \\
\hline & 3 & $1.02 \pm 0.50$ & $10.18 \pm 6.04$ & $6.08 \pm 1.82$ & $0.96 \pm 0.02$ & & & \\
\hline \multirow{3}{*}{$\mathrm{EF}$} & 1 & $0.10 \pm 0.00$ & $14.70 \pm 12.73$ & $2.76 \pm 2.10$ & $0.98 \pm 0.03$ & \multirow{3}{*}{$15.31 \pm 4.64$} & \multirow{3}{*}{$0.48 \pm 0.27$} & \multirow{3}{*}{$0.0037 \pm 0.0023$} \\
\hline & 2 & $0.90 \pm 1.41$ & $8.36 \pm 2.73$ & $7.94 \pm 2.54$ & $0.98 \pm 0.02$ & & & \\
\hline & 3 & $0.40 \pm 0.33$ & $6.72 \pm 1.05$ & $5.29 \pm 1.06$ & $0.98 \pm 0.01$ & & & \\
\hline \multirow{2}{*}{$\mathrm{CF}$} & 1 & $0.10 \pm 0.00$ & $8.36 \pm 2.95$ & $3.12 \pm 1.81$ & $0.98 \pm 0.02$ & \multirow{2}{*}{$11.37 \pm 4.92$} & \multirow{2}{*}{$0.66 \pm 0.01$} & \multirow{2}{*}{$0.0034 \pm 0.0006$} \\
\hline & 2 & 0.100 .00 & $4.68 \pm 2.02$ & $1.47 \pm 0.88$ & $0.97 \pm 0.04$ & & & \\
\hline \multirow{2}{*}{$\mathrm{S}$} & 1 & $0.86 \pm 0.96$ & $12.72 \pm 2.49$ & $5.93 \pm 1.88$ & $0.97 \pm 0.03$ & \multirow{2}{*}{$12.59 \pm 1.12$} & \multirow{2}{*}{$0.32 \pm 0.04$} & \multirow{2}{*}{$0.0014 \pm 0.0005$} \\
\hline & 2 & $2.06 \pm 1.61$ & $14.74 \pm 1.37$ & $8.41 \pm 2.08$ & $0.96 \pm 0.03$ & & & \\
\hline \multirow{3}{*}{ G } & 1 & $0.88 \pm 0.65$ & $12.64 \pm 1.63$ & $8.97 \pm 2.12$ & $0.98 \pm 0.01$ & \multirow{3}{*}{$23.05 \pm 11.20$} & \multirow{3}{*}{$0.22 \pm 0.06$} & \multirow{3}{*}{$0.0014 \pm 0.0003$} \\
\hline & 2 & $1.12 \pm 0.98$ & $13.20 \pm 2.14$ & $8.57 \pm 1.05$ & $0.97 \pm 0.02$ & & & \\
\hline & 3 & $2.98 \pm 2.37$ & $19.46 \pm 3.73$ & $14.53 \pm 3.29$ & $0.96 \pm 0.03$ & & & \\
\hline
\end{tabular}

${ }^{1}$ UF correspond to depth of uniform flow (matrix flow). ${ }^{2}$ ID correspond to infiltration depth. ${ }^{3}$ DC correspond to dye coverage. ${ }^{4}$ PF correspond to preferential flow fraction. ${ }^{5} \mathrm{Li}$ correspond to length index of preferential flow. ${ }^{6} \mathrm{CV}$ correspond to variation coefficient of dye coverage in preferential flow area. ${ }^{7} \mathrm{C} \mu$ correspond to variation coefficients of maximum infiltration depths. 
Table 3. Characteristic parameters of preferential flow variables. (G15). (average value \pm standard deviation).

\begin{tabular}{|c|c|c|c|c|c|c|c|c|}
\hline Site Type & Sample Number & $\mathrm{UF} / \mathrm{cm}$ & $\mathrm{ID} / \mathrm{cm}$ & $\mathrm{DC} / \%$ & $\mathrm{PF} / \%$ & $\mathrm{Li} / \%$ & $\mathrm{CV}$ & $\mathrm{C} \mu$ \\
\hline \multirow{2}{*}{ SF } & 1 & $2.08 \pm 1.13$ & $22.78 \pm 8.97$ & $10.17 \pm 1.98$ & $0.96 \pm 0.01$ & \multirow{2}{*}{$17.65 \pm 4.51$} & \multirow{2}{*}{$0.42 \pm 0.21$} & \multirow{2}{*}{$0.0028 \pm 0.0002$} \\
\hline & 2 & $0.10 \pm 0.06$ & $11.72 \pm 3.29$ & $3.77 \pm 2.12$ & $0.99 \pm 0.01$ & & & \\
\hline \multirow{3}{*}{ PY } & 1 & $2.50 \pm 1.78$ & $14.02 \pm 7.41$ & $9.22 \pm 4.70$ & $0.95 \pm 0.02$ & \multirow{3}{*}{$33.50 \pm 7.59$} & \multirow{3}{*}{$0.45 \pm 0.09$} & \multirow{3}{*}{$0.0030 \pm 0.0011$} \\
\hline & 2 & $3.60 \pm 0.74$ & $16.18 \pm 3.87$ & $12.91 \pm 4.13$ & $0.94 \pm 0.01$ & & & \\
\hline & 3 & $3.42 \pm 2.77$ & $13.82 \pm 4.59$ & $11.94 \pm 4.54$ & $0.95 \pm 0.04$ & & & \\
\hline \multirow{3}{*}{$\mathrm{EF}$} & 1 & $1.48 \pm 1.40$ & $13.20 \pm 2.98$ & $7.76 \pm 2.22$ & $0.97 \pm 0.03$ & \multirow{3}{*}{$17.94 \pm 3.24$} & \multirow{3}{*}{$0.40 \pm 0.17$} & \multirow{3}{*}{$0.0019 \pm 0.0003$} \\
\hline & 2 & $0.46 \pm 0.46$ & $16.72 \pm 2.69$ & $7.60 \pm 1.74$ & $0.99 \pm 0.01$ & & & \\
\hline & 3 & $1.88 \pm 1.81$ & $14.12 \pm 3.63$ & $7.14 \pm 4.05$ & $0.96 \pm 0.03$ & & & \\
\hline \multirow{2}{*}{$\mathrm{CF}$} & 1 & $0.18 \pm 0.16$ & $15.40 \pm 3.88$ & $5.30 \pm 2.12$ & $0.99 \pm 0.00$ & \multirow{2}{*}{$13.57 \pm 3.87$} & \multirow{2}{*}{$0.41 \pm 0.04$} & \multirow{2}{*}{$0.0029 \pm 0.0006$} \\
\hline & 2 & $0.94 \pm 0.72$ & $7.98 \pm 3.25$ & $5.06 \pm 1.68$ & $0.97 \pm 0.02$ & & & \\
\hline \multirow{2}{*}{ S } & 1 & $1.58 \pm 1.12$ & $14.76 \pm 5.02$ & $7.36 \pm 1.96$ & $0.96 \pm 0.02$ & \multirow{2}{*}{$20.79 \pm 0.60$} & \multirow{2}{*}{$0.27 \pm 0.03$} & \multirow{2}{*}{$0.0022 \pm 0.0008$} \\
\hline & 2 & $1.72 \pm 0.82$ & $13.56 \pm 2.54$ & $8.27 \pm 1.81$ & $0.96 \pm 0.01$ & & & \\
\hline \multirow{3}{*}{ G } & 1 & $2.22 \pm 2.29$ & $16.52 \pm 1.21$ & $17.35 \pm 2.27$ & $0.97 \pm 0.02$ & \multirow{3}{*}{$26.16 \pm 3.49$} & \multirow{3}{*}{$0.20 \pm 0.04$} & \multirow{3}{*}{$0.0009 \pm 0.0003$} \\
\hline & 2 & $0.98 \pm 1.12$ & $15.70 \pm 2.71$ & $11.66 \pm 2.63$ & $0.98 \pm 0.02$ & & & \\
\hline & 3 & $0.74 \pm 1.23$ & $16.82 \pm 1.49$ & $12.54 \pm 2.29$ & $0.99 \pm 0.02$ & & & \\
\hline
\end{tabular}


Table 4. Characteristic parameters of preferential flow variables. (G35). (average value \pm standard deviation).

\begin{tabular}{|c|c|c|c|c|c|c|c|c|}
\hline Site Type & Sample Number & $\mathrm{UF} / \mathrm{cm}$ & $\mathrm{ID} / \mathrm{cm}$ & $\mathrm{DC} / \%$ & $\mathrm{PF} / \%$ & $\mathrm{Li} / \%$ & $\mathrm{CV}$ & $\mathrm{C} \mu$ \\
\hline \multirow{2}{*}{ SF } & 1 & $0.40 \pm 0.60$ & $17.34 \pm 2.65$ & $9.16 \pm 3.52$ & $0.99 \pm 0.01$ & \multirow{2}{*}{$26.42 \pm 0.59$} & \multirow{2}{*}{$0.37 \pm 0.06$} & \multirow{2}{*}{$0.0012 \pm 0.000$} \\
\hline & 2 & $0.12 \pm 0.04$ & $16.7 \pm 1.95$ & $10.33 \pm 2.92$ & $1.00 \pm 0.00$ & & & \\
\hline \multirow{2}{*}{ PY } & 1 & $1.32 \pm 1.22$ & $9.22 \pm 2.73$ & $7.07 \pm 2.29$ & $0.97 \pm 0.03$ & \multirow{2}{*}{$19.17 \pm 5.69$} & \multirow{2}{*}{$0.34 \pm 0.02$} & \multirow{2}{*}{$0.0018 \pm 0.0003$} \\
\hline & 2 & $1.82 \pm 0.99$ & $14.34 \pm 2.41$ & $10.15 \pm 2.95$ & $0.97 \pm 0.02$ & & & \\
\hline \multirow{3}{*}{$\mathrm{EF}$} & 1 & $1.80 \pm 1.20$ & $7.24 \pm 1.78$ & $7.05 \pm 0.97$ & $0.95 \pm 0.03$ & \multirow{3}{*}{$11.84 \pm 6.01$} & \multirow{3}{*}{$0.27 \pm 0.13$} & \multirow{3}{*}{$0.0026 \pm 0.0008$} \\
\hline & 2 & $0.88 \pm 0.39$ & $10.20 \pm 2.60$ & $4.77 \pm 0.82$ & $0.96 \pm 0.01$ & & & \\
\hline & 3 & $0.88 \pm 0.78$ & $6.92 \pm 3.45$ & $5.48 \pm 2.24$ & $0.97 \pm 0.02$ & & & \\
\hline \multirow{2}{*}{$\mathrm{CF}$} & 1 & $0.14 \pm 0.08$ & $5.10 \pm 2.04$ & $3.75 \pm 0.73$ & $0.99 \pm 0.00$ & \multirow{2}{*}{$8.04 \pm 0.13$} & \multirow{2}{*}{$0.18 \pm 0.04$} & \multirow{2}{*}{$0.0033 \pm 0.0002$} \\
\hline & 2 & $0.28 \pm 0.22$ & $6.78 \pm 2.37$ & $4.46 \pm 0.57$ & $0.99 \pm 0.01$ & & & \\
\hline \multirow{2}{*}{$\mathrm{S}$} & 1 & $0.10 \pm 0.00$ & $7.64 \pm 2.15$ & $5.40 \pm 0.75$ & $1.00 \pm 0.00$ & \multirow{2}{*}{$14.77 \pm 3.97$} & \multirow{2}{*}{$0.21 \pm 0.05$} & \multirow{2}{*}{$0.0018 \pm 0.0003$} \\
\hline & 2 & $1.76 \pm 1.00$ & $9.82 \pm 1.81$ & $7.90 \pm 1.82$ & $0.96 \pm 0.02$ & & & \\
\hline \multirow{3}{*}{ G } & 1 & $5.28 \pm 1.67$ & $22.08 \pm 1.48$ & $19.81 \pm 2.57$ & $0.95 \pm 0.01$ & \multirow{3}{*}{$35.19 \pm 7.41$} & \multirow{3}{*}{$0.19 \pm 0.04$} & \multirow{3}{*}{$0.0008 \pm 0.0002$} \\
\hline & 2 & $6.72 \pm 1.27$ & $22.46 \pm 2.76$ & $23.74 \pm 3.30$ & $0.94 \pm 0.01$ & & & \\
\hline & 3 & $3.96 \pm 2.34$ & $19.36 \pm 1.61$ & $17.67 \pm 3.72$ & $0.96 \pm 0.02$ & & & \\
\hline
\end{tabular}


Table 5. Characteristic parameters of preferential flow variables. (G55). (average value \pm standard deviation).

\begin{tabular}{|c|c|c|c|c|c|c|c|c|}
\hline Site Type & Sample Number & $\mathrm{UF} / \mathrm{cm}$ & $\mathrm{ID} / \mathrm{cm}$ & $\mathrm{DC} / \%$ & $\mathrm{PF} / \%$ & $\mathrm{Li} / \%$ & $\mathrm{CV}$ & $\mathrm{C} \mu$ \\
\hline \multirow{2}{*}{ SF } & 1 & $0.56 \pm 0.74$ & $25.94 \pm 3.52$ & $18.39 \pm 3.41$ & $0.99 \pm 0.01$ & \multirow{2}{*}{$26.85 \pm 1.46$} & \multirow{2}{*}{$0.21 \pm 0.01$} & \multirow{2}{*}{$0.0010 \pm 0.000$} \\
\hline & 2 & $0.40 \pm 0.28$ & $25.40 \pm 3.30$ & $19.48 \pm 3.86$ & $1.00 \pm 0.00$ & & & \\
\hline \multirow{2}{*}{ PY } & 1 & $2.66 \pm 3.77$ & $25.26 \pm 4.26$ & $14.84 \pm 8.45$ & $0.98 \pm 0.03$ & \multirow{2}{*}{$29.48 \pm 1.74$} & \multirow{2}{*}{$0.58 \pm 0.05$} & \multirow{2}{*}{$0.1376 \pm 0.1363$} \\
\hline & 2 & $3.58 \pm 3.81$ & $22.58 \pm 8.29$ & $15.77 \pm 7.50$ & $0.96 \pm 0.03$ & & & \\
\hline \multirow{3}{*}{$\mathrm{EF}$} & 1 & $0.44 \pm 0.68$ & $9.66 \pm 3.25$ & $6.67 \pm 2.23$ & $0.99 \pm 0.01$ & \multirow{3}{*}{$21.14 \pm 11.60$} & \multirow{3}{*}{$0.38 \pm 0.15$} & \multirow{3}{*}{$0.0032 \pm 0.0014$} \\
\hline & 2 & $0.10 \pm 0.00$ & $8.04 \pm 1.35$ & $4.15 \pm 0.77$ & $1.00 \pm 0.00$ & & & \\
\hline & 3 & $0.62 \pm 0.85$ & $13.34 \pm 7.42$ & $7.46 \pm 3.78$ & $0.99 \pm 0.01$ & & & \\
\hline \multirow{2}{*}{$\mathrm{CF}$} & 1 & $0.14 \pm 0.08$ & $3.86 \pm 0.89$ & $2.05 \pm 0.77$ & $0.98 \pm 0.01$ & \multirow{2}{*}{$6.78 \pm 1.79$} & \multirow{2}{*}{$0.39 \pm 0.03$} & \multirow{2}{*}{$0.0032 \pm 0.0012$} \\
\hline & 2 & $0.10 \pm 0.00$ & $7.28 \pm 3.35$ & $2.94 \pm 0.93$ & $0.99 \pm 0.00$ & & & \\
\hline \multirow{2}{*}{$S$} & 1 & $0.74 \pm 0.59$ & $8.46 \pm 1.65$ & $7.12 \pm 2.06$ & $0.98 \pm 0.02$ & \multirow{2}{*}{$27.00 \pm 14.20$} & \multirow{2}{*}{$0.42 \pm 0.10$} & \multirow{2}{*}{$0.0024 \pm 0.0009$} \\
\hline & 2 & $3.14 \pm 1.83$ & $18.92 \pm 7.65$ & $13.54 \pm 6.36$ & $0.96 \pm 0.02$ & & & \\
\hline \multirow{3}{*}{ G } & 1 & $3.26 \pm 2.07$ & $29.44 \pm 2.40$ & $26.03 \pm 4.08$ & $0.98 \pm 0.01$ & \multirow{3}{*}{$44.39 \pm 6.20$} & \multirow{3}{*}{$0.16 \pm 0.03$} & \multirow{3}{*}{$0.0007 \pm 0.0001$} \\
\hline & 2 & $0.56 \pm 0.63$ & $24.40 \pm 1.84$ & $21.46 \pm 2.11$ & $1.00 \pm 0.01$ & & & \\
\hline & 3 & $6.66 \pm 3.85$ & $27.84 \pm 2.13$ & $29.15 \pm 4.99$ & $0.96 \pm 0.02$ & & & \\
\hline
\end{tabular}

Table 6. PC coefficient (principal component analysis) of each index.

\begin{tabular}{lcccccccccc}
\hline Index & CLA & PF & CV & P & P1 & P2 & P5 & P3 & P4 & C $\boldsymbol{~}$ \\
\hline PC coefficient & 0.19 & 0.18 & 0.15 & 0.08 & 0.07 & 0.07 & 0.02 & 0.01 & 0.01 & -0.03 \\
\hline Index & P6 & $\mathrm{K}$ & $\mathrm{RF}$ & $\mathrm{Sa}$ & $\mathrm{Si}$ & $\mathrm{Ks}$ & $\mathrm{ID}$ & $\mathrm{Li}$ & $\mathrm{DC}$ & $\mathrm{UF}$ \\
\hline PC coefficient & -0.03 & -0.03 & -0.04 & -0.09 & -0.16 & -0.20 & -0.20 & -0.25 & -0.27 & -0.29 \\
\hline
\end{tabular}


Compared with the calculation of Pearson's correlation coefficient, SEM can reduce the interference of correlation estimation between potential variables caused by measurement error. Two hundred ninety samples of vertical section are used in this study. This number meets James Stevens' standard of at least 15 samples for each factor in standard multiple regression analysis. This analysis method is thus feasible.

The path diagram of SEM is established after several modifications (Figure 4). We use the maximum likelihood to simulate and correct the model in accordance with critical ration (CR); when $C R>2$, the path coefficient is considerably different from 0 at $95 \%$ confidence. The $C R$ absolute value of each observation variable is greater than 2, and the SEM indexes (absolute fit index and relative fitting index) are all meets the standard, indicating that the model in Figure 4 is available. Table 7 lists the significantly correlated factors, the significance of path coefficient, standard error, and critical ratio (CR) [42]. The significant correlation between measurement variables (clay content, amount of ponded water infiltration, uniform infiltration depth) and potential variables (erodibility factor (EPIC), preferential flow fraction) is calculated on the premise that measurement errors are allowed and the direction of their interaction. We can judge the influence of each factor according to the size and positive and negative of the standardized path coefficient and judge the influence direction of each factor according to the direction of the standardized path.

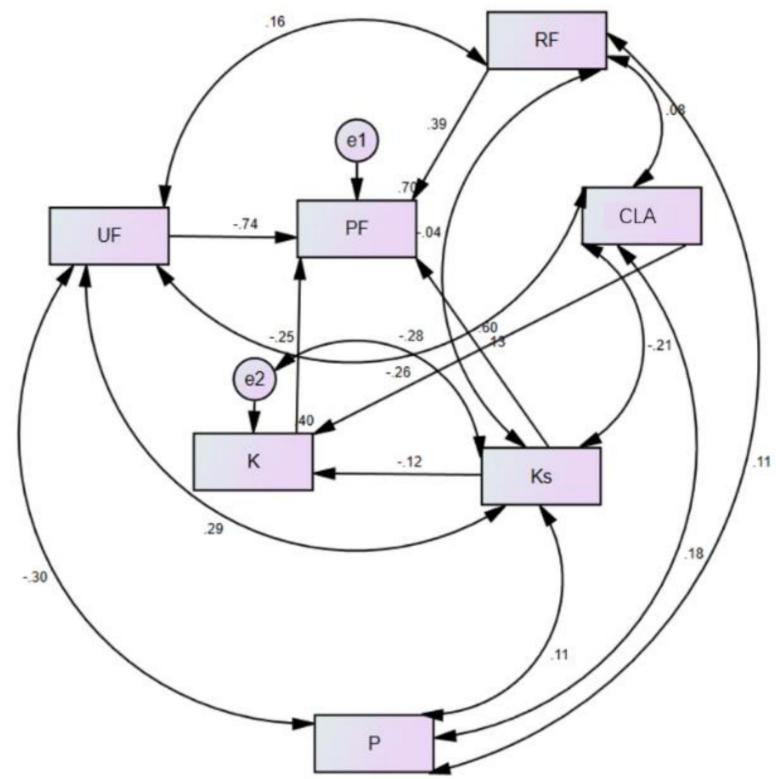

Figure 4. SEM of the characteristic parameters of preferential flow and typical characteristic values of influencing factors (e represents the errors).

Table 7. Covariance results of SEM variables.

\begin{tabular}{cccccccc}
\hline & Path & & Non-Standardised Estimate & S.E. ${ }^{6}$ & $\mathbf{C R}^{7}$ & $\mathbf{P}^{8}$ & $\begin{array}{c}\text { Standardised Path } \\
\text { Coefficient Estimation }\end{array}$ \\
\hline $\mathrm{K}^{1}$ & $<-$ & $\mathrm{CLA}$ & $-128,679.21$ & $25,721.89$ & -5.00 & $* * * 9$ & -0.60 \\
$\mathrm{PF}^{3}$ & $<-$ & $\mathrm{RF}^{4}$ & 0.00 & 0.00 & 5.22 & $* * *$ & 0.39 \\
$\mathrm{PF}$ & $<-$ & $\mathrm{UF}^{5}$ & -0.01 & 0.00 & -9.49 & $* * *$ & -0.74 \\
$\mathrm{PF}$ & $<-$ & $\mathrm{K}$ & 0.00 & 0.00 & -3.37 & $* * *$ & -0.26 \\
\hline
\end{tabular}

${ }^{1} \mathrm{~K}$ corresponds to the erodibility factor (EPIC). ${ }^{2}$ CLA corresponds to clay content. ${ }^{3}$ PF corresponds to preferential flow fraction. ${ }^{4} \mathrm{RF}$ corresponds to the simulated amount of ponded water infiltration. ${ }^{5} \mathrm{UF}$ corresponds to uniform infiltration depth. ${ }^{6}$ S.E. corresponds to the smallest eigenvalue. ${ }^{7} \mathrm{CR}$ corresponds to critical ration. ${ }^{8} \mathrm{P}$ corresponds to the probability of obtaining the critical ratio in absolute value. ${ }^{9 * * *}$ corresponds to the probability of obtaining the critical ratio in absolute value is less than 0.001 . In other words, the regression weight is significantly different from zero at the 0.001 level (two-tailed). 


\section{Discussion}

\subsection{Characteristics of Preferential Flow under Different Precipitation Conditions}

The quantitative description of the characteristic parameters of preferential flow (such as infiltration depth, depth of matrix flow, dye coverage, preferential flow fraction and length index) indicates that the development degree of matrix and preferential flow is related to the infiltration amount of surface water and an increase in infiltration water can promote the depth and proportion of matrix flow to a certain extent. Tables $2-5$ show that an increase in infiltration water can increase the dyeing area of soil profile to a certain extent [28]. Under certain soil pore structure conditions, the more surface water is accumulated, the greater the depth of the surface matrix flow, and the more preferential flow is developed in soil. Figure 2 presents that the existence of preferential flow in the dyed image is difficult to identify under the condition of G5, indicating that the formation of preferential flow is difficult to trigger under the condition of limited surface water; this result is similar to the conclusion of Edwards et al. (1993) [43] and Guo et al. (2018) [44].

The preferential flow phenomenon under G15 is evident, but that under G35 is the most apparent. Under G55, the dyeing area distribution is large and the depth of matrix flow is deep. Thus, the large pores in the shallow layer of the surface are connected into a network structure when they reach saturation, thus enhancing surface hydraulic connectivity and allowing the preferential flow of the shallow soil to become matrix flow; this finding is similar to the conclusions of Sidle et al. (2001) [45]. Therefore, in a future simulation experiment of soil water infiltration, the water infiltration experiment of 15-35 mm can be clearly visualized. If the depth of surface water is less than $15 \mathrm{~mm}$, then the water preferential infiltration path of the test plot may be impossible to obtain. If the surface water depth is greater than $55 \mathrm{~mm}$, then the shallow surface's preferential flow may be forced to develop into matrix flow.

However, the data in Tables 4 and 5 indicate that the parameters of each preferential flow are similar under the G35 and G55 conditions. For example, the depth of matrix flow of G35 is greater than that of G55, whereas the infiltration depth, dye coverage, preferential flow fraction, length index, variation coefficient of dye coverage in preferential flow area (CV)and variation coefficients of maximum infiltration depths $(\mathrm{C} \mu)$ of G55 are greater than those of G35. This result indicates that when the surface water reaches $35 \mathrm{~mm}$, the matrix flow has reached the limit; when the surface water reaches $55 \mathrm{~mm}$, the preferential flow can still be developed. These indications are similar to the study of Gerke et al. (2015) [46]. The C $\mu$ of G55 is 10 times higher than that of the three other conditions, indicating that substantial water accumulation affects the variability of the maximum infiltration depth in extreme events.

\subsection{Preferential Flow Characteristics under Different Vegetation Characteristics}

Compared with the preferential flow phenomenon under different environment conditions, the preferential flow advantage of forestland is more evident than that of grassland and the heterogeneity of the preferential flow of secondary forestlands is the strongest. The preferential flow of plantation forestland is normal and concentrated, and the substrate flow of grassland is advantageous.

In the $0-5 \mathrm{~cm}$ shallow soil, matrix flow occurs. The most obvious phenomenon is matrix flow in grassland, and the depth of matrix flow is the largest. The phenomenon of matrix flow in secondary forestlands, Platycladus orientalis (L.) Francoptmxjjkmsc cypress plantation forestland, and Eucalyptus robusta Smith plantation forestland is unobvious. The vegetation survey shows that the scrubland and grassland coverage of secondary forestlands, Pinus yunnanensis Franch. var. tenuifolia plantation forestland, Eucalyptus robusta Smith plantation forestland, Platycladus orientalis (L.) Francoptmxjjkmsc cypress plantation forestland, scrubland and grassland is approximately $61 \%, 27 \%, 41 \%, 48 \%, 95 \%$ and $100 \%$, respectively. We analyze the correlation between the preferential flow index and the surface vegetation coverage and determine that the surface coverage and variation coefficient of dye coverage in preferential flow area (CV) 
are considerably negatively correlated (the Spearman's correlation coefficient is $-0.886, p<0.05$ ). A correlation exists between the development of preferential flow and vegetation coverage; this finding is similar to those of Stumpp et al. (2010) [8] and Yi et al. (2019) [47]. In the deep soil layer $(>5 \mathrm{~cm})$, the preferential flow characteristics under different experiment conditions are evident and the water infiltration of forestland largely depends on the root system and fissures, such as the fissure between rock and soil $[25,48]$. These fissures can preferentially transport water to the deep soil, which may be related to the special soil structure and high heterogeneity in karst regions [49].

Although preferential flow fraction and length index are parameters that measure preferential flow, length index can also reflect the difference between the preferential and matrix flows [50]. Length index of grassland is the largest, whereas that of cypress forest is the smallest. This result indicates that the development of matrix flow is not improved, and the contrast degree of preferential and matrix flows is low. The species and coverage of the undergrowth vegetation of plantations are considerably less than those of secondary forestlands. Hence, the undergrowth vegetation should be increased during the restoration of the plantations. However, preferential flow fraction mainly focuses on the difference between the preferential and matrix flows amongst different soil layers. The preferential flow fraction value of secondary forestlands is the largest, indicating that the water movement speed of natural forest is the fastest; if remarkable infiltration occurs in the continuous rainfall, then slope stability is easily affected. The preferential flow fraction of cypress forest is largest in the artificial forest, demonstrating that the preferential and matrix flows between different soil layers of secondary forestlands and cypress forest are apparent. Therefore, the underground root channels of cypress forest may be more abundant than those of other forest species and are conducive to the formation of preferential flow.

Variation coefficient of dye coverage in preferential flow area $(\mathrm{CV})$ can reveal the horizontal spatial variation characteristics of preferential flow [51]. In Tables 2-5, PY $>$ CF $>$ EF $>$ SF $>$ S $>$ G indicates that the horizontal transport capacity of the preferential flow of plantations is good and lateral flow is developed. This condition may be related to the thin soil layer and the high probability of the rapid growth of the plantations, leading to the lateral growth of the root system and other reasons; this finding is similar to the conclusions of Noguchi et al. (1999) [52] and Jiang et al. (2019) [53]. A change in variation coefficients of maximum infiltration depths $(C \mu)$ can reveal the spatial variation characteristics of water infiltration depth. The variation in the infiltration depth of plantations is large, and the infiltration depth has strong spatial dependence. A comparison of the characteristic parameters of preferential flow of the six site types shows that the greater the vegetation coverage is, the greater the depth of matrix flow, and the greater the preferential flow of forests is. The vertical infiltration of water in secondary forestlands deepens in sufficient time, but the spatial variability of plantations is large. The infiltration degree of lateral water is better than that of vertical water.

\subsection{Correlation of Characteristic Parameters}

The relationship amongst the eight indicators of clay content, preferential flow fraction, total porosity of the soil, soil erodibility, simulated amount of ponded water infiltration, saturated conductivity of soil and depth of matrix flow is analyzed via SEM error, as shown in Figure 4 and Table 7. Amongst them, depth of matrix flow has a significant negative correlation with preferential flow fraction (the standardized estimate is -0.79), whereas RF has a significant positive correlation with preferential flow fraction (the standardized estimate is 0.40 ). This result shows that an increase in the depth of matrix flow inhibits the development of preferential flow, whereas an increase in rainfall increases the preferential flow ratio. This finding is consistent with the results of Yao et al. (2017) [39].

When the vegetation coverage is high, the underground roots are relatively developed. The growth of the root system helps the surface water infiltrate into the ground preferentially, thus reducing the possibility of matrix flow formation and increasing the possibility of preferential flow formation. The conclusion on the relationship between vegetation coverage and preferential flow development is in contrast to that of Li et al. (2009) [54]. Li et al. (2009) [54] focused on the relationship between 
long-term root activity and preferential flow and ignored the existence of matrix flow under the condition of short-term rainfall. By contrast, the current study focuses on the water infiltration $24 \mathrm{~h}$ before surface ponding. The conclusions are consequently different.

Few studies focus on the relationship between surface vegetation richness and soil saturated hydraulic conductivity in the preferential flow phenomenon. When soil is saturated with water, the greater the vegetation coverage is and the less the water that passes through the unit area under unit water potential gradient and unit time. This result may be due to the increase in vegetation coverage on the surface and the increase in the content of shallow roots in the ground, which increase the connectivity of the surface macropores $[8,55]$. The results show that the lateral richness of underground roots increases, that is, the curvature of water preferential flow path is increased. When the soil layer with the same depth is infiltrated, it must undergo a long preferential infiltration path. Therefore, on the premise of soil saturation, the importance value of vegetation may inhibit the soil saturation and water conductivity.

Soil erodibility has a remarkable negative correlation with preferential flow fraction (the standardized estimate is -0.27$)$, indicating that an increase in soil erodibility may inhibit the development of preferential flow. Nevertheless, the soil erodibility is calculated in accordance with the soil particle size composition and organic matter, but the formula structure is complex. Figure 4 presents that clay content is positively related to soil erodibility, that is, a high clay content may improve soil erodibility; by contrast, soil erodibility is negatively related with preferential flow fraction, that is, an increase in clay content may decrease preferential flow fraction. The larger the soil erodibility is, the smaller the preferential flow ratio is; consequently, the clay content is less. The high content of organic matter hinders the development of macropore flow; this finding is similar to that of Koestel et al. (2012) [56] and Ilek et al. (2019) [57]. Depth of matrix flow is negatively correlated with preferential flow fraction, and an increase in clay content promotes depth of matrix flow. This finding contradicts the conclusions of Horn et al. (1994) [58] and Felde et al. (2019) [59], that is, a high clay content stabilizes macropore structure. The difference may be due to the special soil properties of karst wherein small particles, such as clay, in surface soil gradually block the fast infiltration channel with water infiltration and in turn promote the development of the surface matrix flow and deepen the distance of the uniform infiltration of surface water.

\section{Conclusions}

Jianshui, as a typical karst region, has primary secondary forest and large area of artificial forest of different species. The characteristics of preferential flow and the distribution of nutrient accumulation under six different environmental conditions are studied through a dye-tracing test and the regular pattern of water infiltration is revealed. This study reflects preferential flow characteristics under different forestlands and water infiltration conditions. The results of this study are applicable to the non-bare land in the downhill position of karst regions. The preferential flow process can reduce the retention time of water in soil. Moreover, it allows water to reach the soil depth rapidly or change from a specific position of the lower slope to surface runoff; some of the water enter the groundwater circulation system. Therefore, preferential flow has an important impact on the distribution of water resources. Preferential flow reduces surface water retention and increases the effective water for the growth of underground roots due to the high surface temperature and large evaporation.

The formation of preferential flow is difficult to trigger under the condition of limited surface water and an increase in surface water causes the continuous development of preferential flow. In future simulation experiments of soil water infiltration, a 15-35 $\mathrm{mm}$ ponding infiltration experiment can clearly visualize the process of water preferential infiltration in the experimental plot. Extreme rainfall events affect the variability of the maximum infiltration depth.

The matrix flow of grassland is advantageous, whereas that of plantations is inadequately developed; hence, we should increase the undergrowth vegetation coverage in plantations. The horizontal water transport capacity of plantation forestlands is good, and spatial heterogeneity is 
strong. Particularly, the preferential flow of the Chinese arborvitae plantation forestland is developed. The underground root channels of the Chinese arborvitae plantation forestland are abundant and conducive to the formation of preferential flow. The preferential flow of secondary forestland is the best and the vertical infiltration depth of water is large in a limited time, thus easily affecting slope stability. The heterogeneity of preferential flow in secondary forestland is the strongest, and the preferential flow in plantation forestlands is normal and concentrated.

During the initial movement of water (within the first $24 \mathrm{~h}$ of water infiltration), an increase in vegetation coverage inhibits the development of matrix flow. The importance value of vegetation may inhibit the saturated hydraulic conductivity of soil, indicating that an increase in soil erodibility may inhibit the development of preferential flow. The increase in soil erodibility hinders the development of macropore flow, and an increase in soil clay content may promote the deepening of matrix flow.

Author Contributions: Conceptualization, X.K. and J.C.; methodology, X.K.; software, X.K.; validation, X.K. and F.H.; formal analysis, X.K.; investigation, X.K. and F.H.; resources, X.K.; data curation, X.K.; writing-Original draft preparation, X.K.; writing-Review and editing, X.K.; visualization, X.K.; supervision, X.K.; project administration, J.C.; funding acquisition, J.C. All authors have read and agreed to the published version of the manuscript.

Funding: This research was funded by Major Science and Technology Program for Water Pollution Control and Treatment (grant No.2018ZX07101005-03-02) and the Fundamental Research Funds for the Central Universities (grant No.2015ZCQ-SB-03).

Acknowledgments: Many thanks to the Jian Shui Forestry Station for offering accommodation and supporting field experiments. Meanwhile, we gratefully acknowledge the editor and reviewers.

Conflicts of Interest: The authors declare no conflict of interest.

\section{References}

1. Jiang, Z.C.; Lian, Y.Q.; Qin, X.Q. Rocky desertification in Southwest China: Impacts, causes, and restoration. Earth Sci. Rev. 2014, 132, 1-12. [CrossRef]

2. Zhang, Z.B.; Peng, X.; Zhou, H.; Lin, H.; Sun, H. Characterizing preferential flow in cracked paddy soils using computed tomography and breakthrough curve. Soil Tillage Res. 2015, 146, 53-65. [CrossRef]

3. Angel Anayya, A.; Ingrid, P.; Raul, M.; Dorothy, J.V.; John, D.M.; Akram, N.A. Estimating preferential flow in Karstic aquifers using statistical mixed Models. Ground Water 2014, 52, 584-596. [CrossRef] [PubMed]

4. Chen, H.; Hu, K.; Nie, Y. Analysis of soil water movement inside a footslope and a depression in a karst catchment, Southwest China. Sci. Rep. 2017, 7, 2544. [CrossRef] [PubMed]

5. Qi, X.; Wang, K.; Zhang, C. Effectiveness of ecological restoration projects in a karst region of southwest China assessed using vegetation succession mapping. Ecol. Eng. 2013, 54, 245-253. [CrossRef]

6. Wang, S.J.; Liu, Q.M.; Zhang, D.F. Karst rocky desertification in southwestern China: Geomorphology, landuse, impact and rehabilitation. Land Degrad. 2004, 15, 115-121. [CrossRef]

7. An, S.S.; Huang, Y.M.; Zheng, F.L. Evaluation of soil microbial indices along a revegetation chronosequence in grassland soils on the Loess Plateau, Northwest China. Appl. Soil Ecol. 2009, 41, 286-292. [CrossRef]

8. Stumpp, C.; Maloszewski, P. Quantification of preferential flow and flow heterogeneities in an unsaturated soil planted with different crops using the environmental isotope delta O-18. J. Hydrol. 2010, 394, 407-415. [CrossRef]

9. Liu, M.X.; Du, W.Z.; Zhang, H.L. Changes of preferential flow path on different altitudinal zones in the three gorges reservoir area, China. Can. J. Soil Sci. 2014, 94, 177-188. [CrossRef]

10. Fu, T.G.; Chen, H.S.; Zhang, W.; Nie, Y.P.; Wang, K.L. Vertical distribution of soil saturated hydraulic conductivity and its influencing factors in a small karst catchment in Southwest China. Environ. Monit. Assess. 2015, 187, 92. [CrossRef]

11. Clothier, B.E.; Green, S.R.; Deurer, M. Preferential flow and transport in soil: Progress and prognosis. Eur. J. Soil Sci. 2008, 59, 2-13. [CrossRef]

12. Mooney, S.J.; Morris, C. Morphological approach to understanding preferential flow using image analysis with dye tracers and X-ray computed tomography. Catena 2008, 73, 204-211. [CrossRef]

13. Bouma, J. Soil morphology and preferential flow along macropores. Agric. Water Manag. 1981, 3, $235-250$. [CrossRef] 
14. Green, R.T.; Bertetti, F.T.; Miller, M.S. Focused groundwater flow in a carbonate aquifer in a semi-arid environment. J. Hydrol. 2014, 517, 284-297. [CrossRef]

15. Jarvis, N.J. A review of non-equilibrium water flow and solute transport in soil macropores: Principles, controlling factors and consequences for water quality. Eur. J. Soil Sci. 2007, 58, 523-546. [CrossRef]

16. Peng, T.; Wang, S.J. Effects of land use, land cover and rainfall regimes on the surface runoff and soil loss on karst slopes in southwest China. Catena 2012, 90, 53-62. [CrossRef]

17. Guo, L.; Lin, H. Critical zone research and observatories: Current status and future perspectives. Vadose Zone J. 2016, 15, 1-14. [CrossRef]

18. Hencher, S.R. Preferential flow paths through soil and rock and their association with landslides. Hydrol. Process. 2010, 24, 1610-1630. [CrossRef]

19. Larsbo, M.; Koestel, J.; Katterer, T.; Jarvis, N. Preferential transport in macropores is reduced by soil organic carbon. Vadose Zone J. 2016, 15, 1-7. [CrossRef]

20. Wang, F.; Chen, H.; Lian, J.; Fu, Z.; Nie, Y. Preferential Flow in Different Soil Architectures of a Small Karst Catchment. Vadose Zone J. 2018, 17. [CrossRef]

21. Vitousek, P.M.; Matson, P.A.; Van Cleve, K. Nitrogen availability and nitrification during succession: Primary, secondary, and old-field seres. Plant Soil 1989, 115, 229-239. [CrossRef]

22. Jarvis, N.; Koestel, J.; Larsbo, M. Understanding preferential flow in the vadose zone: Recent advances and future prospects. Vadose Zone J. 2016, 15. [CrossRef]

23. Koestel, J.; Jorda, H. What determines the strength of preferential transport in undisturbed soil under steady-state flow? Geoderma 2014, 217, 144-160. [CrossRef]

24. Ma, Y.J.; Li, X.Y.; Guo, L.; Lin, H. Hydropedology: Interactions between pedologic and hydrologic processes across spatiotemporal scales. Earth Sci. Rev. 2017, 171, 181-195. [CrossRef]

25. Sohrt, J.; Ries, F.; Sauter, M.; Lange, J. Significance of preferential flow at the rock soil interface in a semi-arid karst environment. Catena 2014, 123, 1-10. [CrossRef]

26. Wang, S.; Chen, H.; Fu, Z.; Wang, K. Evaluation of the spatial pattern of surface soil water content of a karst hillslope in Southwest China using a state-space approach. Arch. Agron. Soil Sci. 2017, 1-14. [CrossRef]

27. Pang, D.; Wang, G.; Li, G.; Sun, Y.; Liu, Y.; Zhou, J. Ecological stoichiometric characteristics of two typical plantations in the karst ecosystem of southwestern China. Forests 2018, 9, 56. [CrossRef]

28. Kan, X.; Cheng, J.; Hu, X.; Zhu, F.; Li, M. Effects of Grass and Forests and the Infiltration Amount on Preferential Flow in Karst Regions of China. Water 2019, 11, 1634. [CrossRef]

29. Dexter, A.R. Advances in Characterization of Soil Structure. Soil Tillage Res. 1988, 11, 199-238. [CrossRef]

30. Dexter, A.R.; Richard, G.; Arrouays, D.; Czyż, E.A.; Jolivet, C.; Duval, O. Complexed organic matter controls soil physical properties. Geoderma 2008, 144, 620-627. [CrossRef]

31. Klute, A.; Dirksen, C. Methods of Soil Analysis: Part 1-Physical and Mineralogical Methods. In Hydraulic Conductivity and Diffusivity: Laboratory Methods; Soil Science Society of America: Madison, WI, USA, 1986; pp. 687-734.

32. Williams, J.R. EPIC-erosion/productivity impact calculator: 2. User manual. USDA. Agric. Res. Serv. 1990, 4, 206-207.

33. Weiler, M.; Naef, F. Simulating surface and subsurface initiation of macropore flow. J. Hydrol. 2003, 273, 139-154. [CrossRef]

34. Mei, X.; Zhu, Q.; Ma, L. Effect of stand origin and slope position on infiltration pattern and preferential flow on a Loess hillslope. Land Degrad. Dev. 2018, 29, 1353-1365. [CrossRef]

35. Lipsius, K.; Mooney, S.J. Using image analysis of tracer staining to examine the infiltration patterns in a water repellent contaminated sandy soil. Geoderma 2006, 136, 865-875. [CrossRef]

36. Alaoui, A.; Caduff, U.; Gerke, H.H. A preferential flow effects on infiltration and runoff in grassland and forest soils. Vadose Zone J. 2011, 10, 367-377. [CrossRef]

37. Ghodrati, M.; Jury, W.A. A field-study using dyes to characterize preferential flow of water. Soil Sci. Soc. Am. J. 1990, 54, 1558-1563. [CrossRef]

38. Hagedorn, F.; Bundt, M. The age of preferential flow paths. Geoderma 2002, 108, 119-132. [CrossRef]

39. Yao, J.; Cheng, J.; Sun, L. Effect of Antecedent Soil Water on Preferential Flow in Four Soybean Plots in Southwestern China. Soil Sci. 2017, 182, 83-93. [CrossRef]

40. Wang, P.; Chen, G.Q. Environmental dispersion in a tidal wetland with sorption by vegetation. Commun. Nonlinear Sci. Numer. Simul. 2015, 22, 348-366. [CrossRef] 
41. Wei, X.; Bi, H.; Liang, W.; Hou, G.; Kong, L.; Zhou, Q. Relationship between Soil Characteristics and Stand Structure of Robinia pseudoacacia L. and Pinus tabulaeformis Carr. Mixed Plantations in the Caijiachuan Watershed: An Application of Structural Equation Modeling. Forests 2018, 9, 124. [CrossRef]

42. Vere, D.T.; Griffith, G.R. Structural econometric modelling in Australia's livestock production and marketing systems: The potential benefits of model integration for industry analysis. Agric. Syst. 2004, 81, 115-131. [CrossRef]

43. Edwards, W.M.; Shipitalo, M.J.; Owens, L.B.; Dick, W.A. Factors affecting preferential flow of water and atrazine through earthworm burrows under continuous no-till corn. J. Environ. Qual. 1993, 22, 453-457. [CrossRef]

44. Guo, L.; Lin, H. Addressing two bottlenecks to advance the understanding of preferential flow in soils. Adv. Agron. Acad. Press 2018, 147, 61-117.

45. Sidle, R.C.; Noguchi, S.; Tsuboyama, Y.; Laursen, K. A conceptual model of preferential flow systems in forested hillslopes: Evidence of self-organization. Hydrol. Process. 2001, 15, 1675-1692. [CrossRef]

46. Gerke, K.M.; Sidle, R.C.; Mallants, D. Preferential flow mechanisms identified from staining experiments in forested hillslopes. Hydrol Process. 2015, 29, 4562-4578. [CrossRef]

47. Yi, J.; Yang, Y.; Liu, M.; Hu, W.; Lou, S.; Zhang, H.; Zhang, D. Characterising macropores and preferential flow of mountainous forest soils with contrasting human disturbances. Soil Res. 2019, 57, 601-614. [CrossRef]

48. Peng, X.; Dai, Q.; Ding, G.; Shi, D.; Li, C. The role of soil water retention functions of near-surface fissures with different vegetation types in a rocky desertification area. Plant Soil. 2019, 441, 587-599. [CrossRef]

49. Zhang, X.; Hu, M.; Guo, X.; Yang, H.; Zhang, Z.; Zhang, K. Effects of topographic factors on runoff and soil loss in Southwest China. Catena 2018, 160, 394-402. [CrossRef]

50. Chen, X.B.; Zhang, H.J.; Cheng, J.H. Quantitative evaluation of preferential flow development degree based on dyed image variability analysis. Trans. CSAM 2015, 46, 93-100.

51. Jiang, X.; Liu, X.; Wang, E. Effects of tillage pan on soil water distribution in alfalfa-corn crop rotation systems using a dye tracer and geostatistical methods. Soil Tillage Res. 2015, 150, 68-77. [CrossRef]

52. Noguchi, S.; Tsuboyama, Y.; Sidle, R.C.; Hosoda, I. Morphological characteristics of macropores and the distribution of preferential flow pathways in a forested slope segment. Soil Sci. Soc. Am. J. 1999, 63, 1413-1423. [CrossRef]

53. Jiang, X.J.; Chen, C.; Zhu, X.; Sissou, Z.; Singh, A.K.; Zhang, W.; Zeng, H.; Yuan, Z.; He, C.; Yu, S.; et al. Use of dye infiltration experiments and HYDRUS-3D to interpret preferential flow in soil in a rubber-based agroforestry systems in Xishuangbanna, China. Catena 2019, 178, 120-131. [CrossRef]

54. Li, X.Y.; Yang, Z.P.; Li, Y.T.; Lin, H. Connecting ecohydrology and hydropedology in desert scrublands: Stemflow as a source of preferential flow in soils. Hydrol. Earth Syst. Sci. 2009, 13, 1133-1144.

55. Maier, F.; van Meerveld, I.; Greinwald, K.; Gebauer, T.; Lustenberger, F.; Hartmann, A.; Musso, A. Effects of soil and vegetation development on surface hydrological properties of moraines in the Swiss Alps. Catena 2019, 187, 104353. [CrossRef]

56. Koestel, J.K.; Moeys, J.; Jarvis, N.J. Meta-analysis of the effects of soil properties, site factors and experimental conditions on solute transport. Hydrol. Earth Syst. Sci. 2012, 16, 1647-1665. [CrossRef]

57. Ilek, A.; Kucza, J.; Witek, W. Using undisturbed soil samples to study how rock fragments and soil macropores affect the hydraulic conductivity of forest stony soils: Some methodological aspects. J. Hydrol. 2019, 570, 132-140. [CrossRef]

58. Horn, R.; Taubner, H.; Wuttke, M.; Baumgartl, T. Soil physical-properties related to soil-structure. Soil Tillage Res. 1994, 30, 187-216. [CrossRef]

59. Felde, V.; Uteau, D.; Peth, S. Soil microaggregates: Effects of clay content on their 3D structure and pore architecture. Geophys. Res. Abstr. 2019, 21, EGU2019-11191.

(C) 2020 by the authors. Licensee MDPI, Basel, Switzerland. This article is an open access article distributed under the terms and conditions of the Creative Commons Attribution (CC BY) license (http://creativecommons.org/licenses/by/4.0/). 